\title{
Clinical Trial Monitoring Visit Report
}

National Cancer Institute

\section{Source}

National Cancer Institute. Clinical Trial Monitoring Visit Report. NCI Thesaurus. Code C115577.

Records describing visits made to a clinical trial site for the evaluation of clinical trial conduct, and regulatory compliance of the site. 